extensive written feedback on related research undertaken by workshop fellows. As a part of their participation, fellows were given two years' membership to APSA and are eligible to apply for small research grants. The second part of the workshop program will be held virtually in summer 2021

APSA's MENA workshops are a multi-year initiative to support political science research and networking in the Arab Middle East and North Africa. For more information visit our website at https://web.apsanet.org/mena/

\section{ARAB POLITICAL SCIENCE NETWORK}

The Arab Political Science Network (APSN) is a collaborative scholarly initiative that supports Arab political scientists in their research, teaching, networking, and professional development. With support from APSA, Carnegie Corporation of New York, and the Ford Foundation, APSN offers a robust slate of activities and events, including workshops for research development and teaching, webinars, grants, and other resources.

Forced to move all activities to a virtual format in response to the COVID-19 pandemic, APSN quickly improvised to develop new programs of support for affected scholars. This included a series of online research feedback sessions in summer 2020 for scholars accepted to the Research Development Workshop, as well as those who received travel grants to attend conferences that were ultimately cancelled due to the pandemic. In December 2020, APSN organized a virtual teaching work- shop focusing on teaching gender politics in the Middle East. This event brough together over 15 multi- and interdisciplinary faculty members teaching women and gender politics inside and outside the Middle East. This was the second of APSN's annual teaching workshop after a December 2019 workshop on teaching international relations, which led to a special forum published in International Studies Perspectives.

APSN also launched a series of public webinars and educational videos (with Arabic subtitles) to extend its virtual support to scholars in the Arab world and beyond. After a successful and well attended first webinar on research in pandemic times in collaboration with Al-Fanar Media, APSN hosted webinars on gender and feminist studies in collaboration with Asfari Institute for Civil Society and Citizenship; a conversation with John Waterbury on higher education policies; and a discussion around researching Arab Americans.

Additional digital resources can be found in the APSN syllabi bank which features syllabi from undergraduate and graduate courses in political science. APSN encourages all scholars, especially those based in the region, who teach courses in political science and relevant interdisciplinary topics to contribute their syllabi in Arabic, English and/or French.

For more information on APSN and their latest projects and events, visit the website at www.arabpsn.org or follow APSN on Twitter or Facebook.

\title{
Resources for Addressing Anti-Asian Hate and Violence
}

$\mathrm{T}$ he American Political Science Association condemns the mass shooting and murder of eight individuals, six of whom were women of Asian descent, in Georgia on Tuesday, March 16, 2021. We condemn this act of racial and ethnic violence and all incidents of racial and ethnic violence and discrimination committed against members of the Asian and Asian American community over the past year.

Political science scholarship provides a framework for understanding the latest eruption of violence against the Asian community in the United States. The racist misogyny, which has roots in America's white supremacist history-including the US government's exclusionary immigration policies of the 19th century, Western colonialist and misogynistic views of Asia and Asian women, and the racist internment of Japanese Americans during WWII, and scapegoating of Asian Americans for phenomena like economic recessions or pandemics-has led to the deadly escalation of anti-Asian and anti-Asian American violent hate incidents since March 2020, according to Stop AAPI Hate.

White supremacy in the United States has fueled discrimination and has obscured and erased the violent realities of anti-Asian American racism from the public narrative. As Drs. Whitney Hua and Jane Junn wrote in the Journal of Race, Ethnicity, and Politics, "[r]acial implicit biases and discrimination against all communities of color, including Asian Americans, are preserved as the racial order continues to exist and normalize them."

Read the full statement at politicalsciencenow.com/apsastatement-condemning-anti-asian-violence-racism-sexismand-historical-exclusion.

APSA has also compiled a list of resources for addressing antiAsian hate and violence, available at: www.apsanet.org/resources/addressinganti-asianhate.

These resources include:

- Data on anti-Asian hate from StopAAPIHate

- Demographic information on Asian Americans and Asian American political behavior from AAPI Data

- A new symposium on AAPI politics in PS: Political Science \& Politics

- Paula D. McClain's 2019 presidential address, "Crises, Race, Acknowledgement: The Centrality of Race, Ethnicity, and Politics to the Future of Political Science."

- Resources on COVID-19 and racism from Asian Americans Advancing Justice and Learning for Justice.

- Information on the Asian Pacific American Caucus (APAC) and the APSA Committee on the Status of Asian Pacific Americans in the Profession 